\title{
AS PSICOPATOLOGIAS COMO DISTÚRBIOS DAS FUNÇÕES DO SELF: UMA CONSTRUÇÃO TEÓRICA NA ABORDAGEM GESTÁLTICA
}

\author{
Psychopathologies as Disorders of the Self Functions: \\ A Theoretical Construction in Gestalt Approach \\ Las Psicopatologías como Disturbios de las Funciones del Self: \\ Una Construcción Teorética en el Abordaje Gestáltica
}

Carlene Maria Dias Tenório

\begin{abstract}
Resumo: Com o objetivo de compreender as psicopatologias com base no DSM-IV e na teoria de F. Perls, o processo de estruturação dos padrões neuróticos, psicóticos e antissociais é descrito a partir dos impasses existenciais, introjeções tóxicas e conflito interno dominador-dominado, que favorecem os distúrbios das fronteiras e funções do self responsáveis pelas dificuldades do sujeito para se diferenciar dos outros, fazer contato pleno com estes, discriminar as demandas internas e externas e agir de modo adequado ao atendimento das mesmas. Nesta perspectiva, supõe-se que, enquanto as psicoses são produzidas pela falência total das fronteiras e funções do self, as neuroses são geradas pelo distúrbio dessas fronteiras e funções, caracterizado pela repetição crônica de interrupções do contato e comportamentos mal adaptativos, que constituem os transtornos de personalidade descritos pelo DSM-IV. Como resultado da articulação entre conceitos, pressupostos, critérios diagnósticos e evidências clínicas são construídas proposições teóricas nas quais os transtornos de personalidade, com exceção do transtorno antissocial, são entendidos como padrões neuróticos de funcionamento desencadeados por distorções primárias e secundárias, negativas e positivas da percepção de "si mesmo" e do "outro", podendo evoluir para transtornos psicóticos em situações de extremo estresse e vulnerabilidade das fronteiras e funções do self.
\end{abstract}

Palavras-chave: Psicopatologia; Distúrbio; Self; Abordagem gestáltica.

\begin{abstract}
In order to understand the psychopathology based on DSM-IV and the theory of F. Perls, the process of structuring neurotic, psychotic and antisocial patterns is described from the existential dilemmas, toxic introjections and a dominator/ dominated internal conflict that favors boundaries disturbances and the functions of the "self" responsible for the difficulties of the subject to differentiate itself from others; making full contact with them; discriminating between internal and external demands and acting appropriately to meet them. From this perspective, it is assumed that, while psychoses are produced by the total failure of boundaries and functions of the "self', the neuroses are generated by the disturbance of these boundaries and "self" functions, characterized by the chronic repetition of interruptions of contact and maladaptive behaviors, which constitute personality disorders described by DSM-IV. As a result of the articulation between concepts, premises, diagnostic criteria and clinical evidence, theoretical propositions are constructed in which personality disorders, except for the antisocial disorder, are perceived as neurotic patterns of functioning triggered by primary and secondary distortions, negative and positive of perception of the "self" and the "other", sometimes progressing to psychotic disorders in situations of extreme stress and vulnerability of boundaries and functions of the "self".
\end{abstract}

Keywords: Psychopathology; Disorder; Self; Gestalt approach.

Resumen: Con el objetivo de comprender las psicopatologías con base en el DSM-IV y en la teoría de F. Perls, el proceso de estructuración de los padrones neuróticos, psicóticos y antisociales es descrito a partir de los impasses existenciales, introyecciones tóxicas y conflicto interno dominador/dominado, que favorecen los disturbios de las fronteras y funciones del self responsables por las dificultades del sujeto para diferenciarse de otros; hacer contacto pleno con estos; discriminar las demandas internas y externas y actuar de modo adecuado al atendimiento de las mismas. En esta perspectiva, se supone que, mientras las psicosis son producidas por la falencia total de las fronteras y funciones del self, las neurosis son generadas por el disturbio de esas fronteras y funciones, caracterizado por la repetición crónica de interrupciones del contacto y comportamientos mal adaptativos, que constituyen los trastornos de personalidad descritos por el DSM-IV. Como resultado de la articulación entre conceptos, presupuestos, criterios diagnósticos y evidencias clínicas son construidas proposiciones teóricas en las cuales los trastornos de personalidad, con excepción del trastorno antisocial, son entendidos como padrones neuróticos de funcionamiento desencadenados por distorsiones primarias y secundarias, negativas y positivas de la percepción de "sí mismo” y del "otro", pudiendo evolucionar para trastornos psicóticos en situaciones de extremo estrés y vulnerabilidad de las fronteras y funciones del self.

Palabras-claves: Psicopatología; Disturbio; Self; Abordaje gestáltica. 


\section{Introdução}

Para Perls (1973/1981), todas as neuroses surgem da incapacidade do indivíduo para encontrar e manter o equilíbrio adequado entre ele e o resto do mundo, e todas têm em comum o sentimento de que os limites do meio se estendem demais sobre si mesmo. O neurótico é o indivíduo sobre quem a sociedade influi demasiadamente e suas interrupções de contato são manobras defensivas para protegê-lo contra a ameaça de ser barrado por um mundo esmagador; são estratégias criadas para manter seu equilíbrio em situações nas quais se vê impotente e dominado pelo "outro", acreditando que as probabilidades estão todas contra ele.

De acordo com o DSM-IV, os transtornos de personalidade se caracterizam por traços de personalidade inflexíveis e mal adaptativos, que causam sofrimento subjetivo e prejuízo funcional significativo para o sujeito. O transtorno de personalidade antissocial é marcado pelo desrespeito e violação das normas sociais e dos direitos alheios, sem sentimento de culpa ou remorso por parte do sujeito, por acreditar que não deve submeter-se a ninguém, para não correr o risco de ser dominado. Nos transtornos psicóticos, os pacientes evidenciam confusão mental, pensamento e comportamento desorganizados, com prejuízo no teste de realidade, manifestando delírios e alucinações.

A hipótese que se defende neste trabalho é de que os sintomas neuróticos ou psicóticos referentes aos Transtornos Clínicos classificados no Eixo I do DSMIV emergem como figura de um fundo constituído pelos transtornos de personalidade apresentados no Eixo II, caracterizados por padrões rígidos de comportamento mantidos pelos distúrbios das funções do self.

\section{Conceituação e Constituição do Self e da Perso- nalidade}

Com base nas elaborações de Perls sobre self e personalidade, compreende-se que o desenvolvimento e o funcionamento saudável dos referidos sistemas dependem, essencialmente, da qualidade da relação, do contato que se estabelece com o "outro", desde os primórdios da existência do indivíduo, uma vez que, para esse teórico, self e personalidade se constituem na fronteira entre organismo e meio.

Sobre isto, Perls, Hefferline e Goodman (1951/1997) esclarecem que selfé o sistema de contatos e de respostas em qualquer momento, diminuindo com o sono, quando há menos necessidade de reagir. Sua atividade é formar figuras e fundos e fazer ajustamentos criativos. Sendo assim, onde há mais conflito, contato e figura/fundo, há mais self; onde há mais confluência, isolamento ou equilíbrio, há um self diminuído. Desse modo, o self não tem consciência de si próprio abstratamente, mas quando está em contato com alguma coisa, uma vez que o mesmo é considerado como sendo a fronteira de contato organismo-meio em funcionamento.

Nessa linha de raciocínio, pode-se dizer que o self se constitui na proporção em que existem diferenciação e interação de limites organismo-meio, sendo, portanto, o "si mesmo", cuja vivência e manifestação se dão na fronteira de contato. Por isso, quanto maior e mais clara for a diferenciação e a delimitação de fronteiras entre o "eu" e o "outro", que normalmente acontece em situações de tensão e conflito, mais claramente o self se fará presente, atuando no meio de forma mais consciente, determinada e agressiva, no sentido de recuperar seu equilíbrio. Em síntese, na abordagem de Perls, o self é o "si mesmo", tal como é vivido e percebido pelo sujeito no contato com o "outro" e consigo mesmo, sendo, portanto, um "eu" relacional, processual e consciente, que se forma e se transforma por meio de ajustamentos criativos, enquanto pensa, sente e age na busca pela satisfação de suas necessidades e atualização de suas potencialidades no campo organismo-meio.

O ajustamento criativo como função essencial do self, pode ser definido como sendo o processo pelo qual o self promove sua autorregulação, criando formas de satisfazer suas necessidades de acordo com as condições do meio, ou transformando essas condições para adequá-las às próprias demandas e capacidades. "Dada a novidade e a variedade indefinida do ambiente, nenhum ajustamento seria possível somente por meio da autorregulação herdada e conservativa; o contato tem de ser uma transformação criativa” (Perls et al., 1951/1997, p. 211).

Considerando que a transformação criativa do campo só acontece se o contato entre organismo e meio for pleno, o ajustamento, quando é feito através de contatos interrompidos, deixa de ser criativo para se tornar conservativo, uma vez que, na interrupção do contato, as necessidades do organismo não são plenamente satisfeitas, as condições do meio não são transformadas, dificultando, assim, a autorrealização e o crescimento do self, embora a preservação de sua estrutura seja garantida. Desse modo, o ajustamento conservativo acontece sempre que o self, na impossibilidade de transformar as circunstâncias do meio, no sentido de promover sua autorrealização, atua basicamente com o objetivo de garantir sua sobrevivência e manter seu equilíbrio no nível em que o ambiente permite, o que implica em abrir mão de seus verdadeiros objetivos e interesses, para adequar-se às exigências externas.

Perls et al. (1951/1997) definem personalidade co-mo sendo o sistema de atitudes adotado nas relações interpessoais:

(...) é a admissão do que somos, que serve de fundamento pelo qual poderíamos explicar nosso comportamento, caso nos fosse pedida uma explicação. Quando o comportamento interpessoal é neurótico, a 
personalidade consiste em alguns conceitos errôneos a respeito de nós próprios, introjetos, ideais de ego, máscaras, etc. (...) a Personalidade é uma espécie de estrutura de atitudes por nós compreendidas, que podem ser empregadas em todo tipo de comportamento interpessoal (pp. 187-188).

Sendo um sistema de atitudes adotado pelo sujeito, que fundamenta a explicação deste sobre o próprio comportamento, a personalidade corresponde à maneira particular de cada um ser no mundo, influenciando e sendo influenciada pela percepção que se tem de "si mesmo", que é construída pela "função personalidade" do self, através da seleção e integração de experiências que se harmonizam com o autoconceito até então assumido pelo sujeito, fazendo com que as demais experiências sejam distorcidas, excluídas da consciência, ou colocadas fora das fronteiras do self.

Além da "função personalidade”, Perls et al. (1951/ 1997) afirmam que o self possui outras duas funções, "id" e "ego" que, juntamente com a "personalidade", correspondem às etapas do processo de ajustamento criativo: pré-contato, contato e pós-contato.

Enquanto "id" e "ego" são funções de autorregulação, nas quais o self interage com o meio, em busca da satisfação de suas necessidades, possibilitando uma consciência vivenciada de "si mesmo", a "personalidade" é uma função de seleção, integração, organização e síntese de experiências vivenciadas na fronteira de contato, propiciando o desenvolvimento de uma consciência representada de self. É como se cada experiência de contato - vivenciada em determinadas circunstâncias, nas quais o sujeito assume atitudes, enquanto desempenha um papel (pai, filho, chefe, subordinado, salvador, vítima, vilão, etc.) - fosse gerada e, ao mesmo tempo, gerasse uma representação de "si mesmo", ou seja, um "eu parcial”, que após ser integrado aos demais, irá fazer parte de um "Eu total”, resultante da organização e síntese de vários "eus parciais". É o "Eu total” que vai permanecer no fundo, influenciando e sendo influenciado pelas atitudes do sujeito em cada situação e pelas representações parciais de "si mesmo".

Enquanto no funcionamento saudável, o "Eu total” está constantemente se reorganizando, a partir da integração de novos "eus parciais" referentes às novas experiências vivenciadas em circunstâncias diferentes, no funcionamento neurótico, onde acontece o distúrbio da "função personalidade”, o "Eu total” tende a permanecer da mesma forma, pois, muitas experiências, que não se harmonizam com sua configuração atual, são negadas ou distorcidas, para que a integridade de sua estrutura seja preservada. Além disso, as representações parciais de self são construídas, principalmente, a partir de mensagens bionegativas introjetadas, como por exemplo: sou covarde e deveria ser mais corajoso; sou acomodado e deveria ser mais esforçado, sou de- sastrado e deveria ser mais cuidadoso, etc. (Tenório, 2003a; 2005).

Nestas condições, a personalidade se caracteriza por padrões rígidos de comportamento determinados por dois tipos de autoconceito, ambos introjetados e distorcidos, um deles referente a um "eu" vivenciado como real (covarde, acomodado e desastrado) e o outro vinculado a um "eu" encarado como ideal (corajoso, esforçado e cuidadoso). Por terem sido originados pela internalização do "outro dominador", tanto o "eu real" quanto o "eu ideal" introjetados irão dominar e sabotar o "eu real" e o "eu ideal" não introjetados construídos a partir de experiências, cujas significações e representações se basearam em avaliações organísmicas. (Tenório, 2003b; 2005)

A “função id", mesmo em sua plena atividade, é caracterizada por uma percepção vaga do meio ambiente, prevalecendo as sensações proprioceptivas, que emergem como figura e produzem reações instantâneas, descomprometidas com as demandas externas. No pré-contato, onde o self funciona através do "id", suas fronteiras ainda não foram totalmente reconstruídas, após serem dissolvidas na experiência recente de pleno envolvimento e troca com o "outro", na fase final do contato com este. Nestas circunstâncias, o self assume características de um "eu” frágil e incipiente, que se comporta de modo irracional e irresponsável, incapaz de fazer ajustamentos criativos, dada a impossibilidade de perceber com clareza, avaliar, enfrentar e transformar deliberadamente seu campo existencial, semelhante ao que acontece no distúrbio da "função ego".

Com base nesse pressuposto, supõe-se que, nas neuroses, o "id" seja a função mais preservada, garantindo a satisfação mínima das necessidades indispensáveis à sobrevivência do self, uma vez que, nessa função, a prioridade do self é garantir seu equilíbrio e sua integridade, através de uma autorregulação herdada e conservativa, mantida por comportamentos reativos, automáticos e impulsivos, nos quais é empregado o menor esforço possível, no sentido de reduzir as tensões vivenciadas no campo organismo-meio. No entanto, nas psicoses, a "função id", como as demais funções do self, encontra-se totalmente anulada, pois, devido ao rompimento das fronteiras, desintegração e fragmentação do "Eu total" em seus diversos "eus parciais", fica impossível manter o equilíbrio mínimo no mundo interno e externo, como também minimizar o sofrimento causado pela desorganização, contradição e incoerência dos pensamentos, sentimentos e comportamentos.

No exercício pleno da "função ego", o selfé vivenciado e se manifesta como um "eu" racional, ativo, determinado e consciente, com capacidade para fazer ajustamentos criativos, na medida em que estabelece claramente suas fronteiras, percebe as demandas do campo, escolhe comportamentos mais apropriados para atendê-las, discriminando o que pertence a "si" e ao "outro", o que é tóxico e nutritivo ao seu organismo, para, em seguida, abrir 
ou fechar suas fronteiras, aceitar (identificar) ou recusar (alienar) o que vem de fora, com o objetivo de promover seu equilíbrio, sua autorrealização e seu crescimento. Esse é o funcionamento saudável, caracterizado pelo fortalecimento das fronteiras e da "função ego" do self, pelo ajustamento criativo, pelo contato não interrompido com o "outro" e consigo mesmo.

Apesar da afirmação de Perls et al. (1951/1997) de que as neuroses resultam da perda da "função ego" do self, o que se pretende mostrar aqui é que tal perda gera as psicoses, enquanto o enfraquecimento ou o distúrbio dessa função gera as neuroses, embora estas, em determinados casos e circunstâncias, possam evoluir para as psicoses. Nesta perspectiva, supõe-se que os sintomas psicóticos podem ser desencadeados por intensos conflitos responsáveis pela completa falência das fronteiras e das funções do self, que já se encontravam debilitadas pelas introjeções tóxicas e consequente luta entre "eu dominador" e "eu dominado". Sendo assim, todo psicótico seria, no fundo, um neurótico, mas nem todo neurótico seria um psicótico, uma vez que a passagem do primeiro para o segundo tipo de transtorno iria depender do nível de vulnerabilidade das funções e das fronteiras do self, bem como da intensidade dos conflitos vivenciados tanto no mundo interno quanto externo.

No distúrbio da "função ego", que acontece nas neuroses, e na perda dessa função, que se dá nas psicoses, as fronteiras do "eu” estão enfraquecidas (neurose), ou rompidas (psicose), desse modo, a consciência das diferenças e a capacidade para discriminar figura e fundo, "eu" e "outro" ficam diminuídas (neurose) ou ausentes (psicose), dificultando (neurose) ou impossibilitando (psicose) a formação e destruição de novas figuras. Com isto, nas neuroses e nas psicoses, a mobilização do organismo é bloqueada ou desfocada, a ação e a interação com o meio são inadequadas ou obsoletas, e o contato final é abortado, impossibilitando a satisfação da necessidade, o fechamento da figura e a recuperação do equilíbrio no campo organismo-meio.

Desse modo, as figuras que ficam em aberto contaminam o campo perceptivo e fazem com que a situação do momento seja avaliada de modo incoerente com a realidade, uma vez que a significação da experiência vivida no aqui e agora é influenciada pelos impasses existenciais do passado, que permanecem mal resolvidos como "microcampos" introjetados. Essa é a explicação para a percepção da realidade parcialmente distorcida nas neuroses, que favorece a repetição de mecanismos de interrupção do contato, a fixação das fronteiras na abertura ou no fechamento e a manutenção de padrões rígidos de comportamentos, que caracterizam os Transtornos da Personalidade. Também é a explicação para a percepção da realidade totalmente distorcida nas psicoses, responsável pela formação dos delírios e alucinações, através da projeção no meio e nos outros dos introjetos tóxicos e dos aspectos alienados do self.
Com relação ao processo de desenvolvimento da personalidade, Perls (1947/2002) entende que suas bases se formam ao longo dos dois primeiros anos de vida, através de estágios que se correlacionam com as etapas de nascimento dos dentes, uma vez que, para esse teórico, o desenvolvimento da capacidade para morder, mastigar e digerir o alimento, ou seja, para desestruturar, transformar e assimilar o que é oferecido pelo meio, é de fundamental importância para a constituição saudável do self e da personalidade.

Quero dizer que o alimento psicológico que nos oferece o mundo externo - o alimento de fatos e atitudes sobre o qual se constroem as personalidades - tem que ser assimilado exatamente da mesma forma que nosso alimento real. Tem que ser desestruturado, analisado, separado e, de novo, reunido sob a forma que nos será mais valiosa. Se for meramente engolido inteiro não contribui para o desenvolvimento de nossas personalidades (Perls, 1973/1981, p. 47)

Neste sentido, o self e a personalidade se desenvolvem no contato com o "outro", através de processos de ajustamentos criativos, nos quais a criança assume, gradativamente, uma postura mais consciente, ativa e independente, na busca pela satisfação de suas necessidades e recuperação de seu equilíbrio no campo organismo-meio. No entanto, para que isto aconteça, é imprescindível que os contatos mantidos com a criança sejam suficientemente saudáveis, para que ela possa se diferenciar do "outro", percebendo-se como ser único, que tem características, necessidades e limites próprios, com capacidade para autorrealizar-se, transformando ou adaptando-se às condições do ambiente que lhe cerca.

O contato saudável é compreendido aqui como um contato pleno e dialógico, que proporciona ao sujeito a experiência de ser respeitado e valorizado pelo "outro" em sua singularidade, semelhante ao que é descrito por Hycner (1995) como "diálogo genuíno” inspirado na filosofia de Buber. Do ponto de vista dialógico, todo "eu” é posterior à relação, pois é no diálogo com o "tu”, diferente e separado do "eu", que se constrói a noção de "si mesmo" e do "outro". Nesta perspectiva, a psicopatologia acontece quando o sujeito, em seus relacionamentos interpessoais, não vivenciou, de modo suficiente, a experiência de ser confirmado pelo "outro" em sua alteridade.

Na descrição de Perls (1947/2002) sobre o desenvolvimento da personalidade, fica implícita a necessidade de se estabelecer contatos satisfatórios com a criança, para que as fronteiras e as funções do self se constituam de forma plena. Isto não quer dizer que a criança, para se desenvolver de forma saudável, deva crescer em um ambiente totalmente permissivo, no entanto, é necessário que, na relação com o "outro" mais significativo, prevaleça o contato pleno e dialógico, onde ambos se coloquem de forma inteira e espontânea, respeitando-se 
mutuamente em suas diferenças, o que torna impossível uma relação sem renúncias, desafios, conflitos e ajustamentos criativos. Por outro lado, todo contato pressupõe diferenciação e troca entre "eu" e "não eu", que implica numa consciência ampla de "si mesmo" e do "outro", mobilização em busca da satisfação mútua, através da criação de estratégias, pelas quais ambos se modificam, adequando-se um ao outro.

(...) quando duas pessoas se encontram, inicia-se o jogo do encontro (...). Assim, elas estão à procura de um interesse comum, ou de um mundo em comum, onde passam repentinamente do eu e você para o nós. Desta forma, surge um novo fenômeno, o nós, que é diferente do eu e você. (...) E quando nos encontramos, então eu mudo e você muda, através do processo de um encontro mútuo (Perls, 1969/1977, p. 21).

Se a criança vivenciar, com frequência, a experiência de ser aceita e confirmada pelo "outro", mais tarde ela poderá estabelecer um diálogo consigo mesma, mantendo contato com todos os aspectos do self, inclusive com aqueles que, aparentemente, são ameaçadores, favorecendo, assim, seu funcionamento saudável. Se ela tiver que ser como os "outros" desejam que ela seja, tendo que negar suas diferenças, para não entrar em conflito com eles, ao invés de uma diferenciação, haverá uma confluência com os mesmos, comprometendo a constituição plena das fronteiras e das funções do self. "Todo indivíduo, toda planta, todo animal tem apenas um objetivo inato - realizar-se naquilo que é" (Perls, 1969/1977, p. 52).

\section{Constituição e Caracterização das Psicopatologias}

O contato interrompido e não dialógico, ao contrário do contato pleno e dialógico, se caracteriza por um tipo de relação dominador-dominado, onde as pessoas assumem atitudes impositivas ou subservientes diante da outra. Nesse contexto, existe uma grande diferenciação e separação mantidas por fronteiras impermeáveis ou fechadas do lado impositivo e dominante, e uma indiferenciação e confluência mantidas por fronteiras muito permeáveis ou abertas do lado subserviente e dominado, dificultando o encontro e a troca entre os dois e favorecendo o desenvolvimento das psicopatologias.

Na relação entre pais e filhos é comum acontecer contatos interrompidos e não dialógicos, principalmente quando os pais são demasiadamente rígidos e autoritários. Nesses casos, os pais não conseguem perceber as reais capacidades e necessidades dos filhos, assumindo atitudes extremamente dominadoras, caracterizadas pela imposição arbitrária de regras e limites, motivados pela necessidade de criarem indivíduos perfeitos, como eles mesmos gostariam, mas não conseguiram ser. Isto faz com que os filhos sejam excessivamente cobrados, controlados e tolhidos completamente em sua liberdade e individualidade.

No entanto, esses contatos interrompidos e não dialógicos também acontecem quando os pais são extremamente permissivos e indulgentes, com dificuldades para impor limites, submetendo-se aos filhos, por medo de frustrá-los e magoá-los. Nesse contexto, os filhos não conseguem crescer emocionalmente, permanecendo com baixa tolerância às frustrações e com medo de enfrentar as adversidades do dia a dia. Esses pais, por serem extremamente imaturos ou problemáticos, não conseguem desempenhar suas funções adequadamente, tornando-se reféns dos próprios filhos. A fragilidade e a submissão dos pais em relação aos filhos faz com que estes tenham uma visão deturpada da realidade, interrompendo o contato com aspectos do self e do ambiente que entram em contradição com suas fantasias e idealizações a respeito de si e do mundo.

No processo de crescimento existem duas escolhas. A criança pode crescer e aprender a superar frustrações, ou pode ser mimada de forma a receber tudo o que quiser, porque a criança deve ter tudo o que o papai nunca teve, ou porque os pais não sabem como frustrar os filhos. (...) Sem frustração não existe necessidade, não existe razão para mobilizar os próprios recursos, para descobrir a própria capacidade para fazer alguma coisa e, a fim de não se frustrar, que é uma experiência muito dolorosa, a criança aprende a manipular o ambiente. (Perls, 1969/1977, pp. 54-55)

Nos relacionamentos em que os pais frustram, reprimem e controlam excessivamente os filhos, a vulnerabilidade das fronteiras da criança, que ainda estão em formação, favorece a introjeção de mensagens nocivas e irrealistas a respeito de "si mesma”, responsável por uma distorção "negativa" da autoimagem, na qual ela passa a se perceber como culpada, má e inadequada. Essa distorção "negativa" também acontece quando a criança é extremamente protegida. A superproteção dos pais reforça a fragilidade e a inferioridade do filho, fazendo com que ele, apesar do avanço de sua idade, continue se percebendo como incapaz de conduzir a própria vida. É essa distorção "negativa" da autoimagem que vai gerar os sentimentos crônicos de impotência e menos valia típicos do funcionamento neurótico.

No contexto familiar em que os filhos são supervalorizados, a imaturidade das fronteiras do self favorece a introjeção de mensagens de engrandecimento irreal, responsável por uma distorção "positiva” da autoimagem, na qual a criança passa a se perceber como alguém especial, dificultando suas relações interpessoais, uma vez que, como defesa, procura se manter fechada, por medo de ser desmascarada pelo "outro" e confrontada com as próprias limitações, ou por não ter interesse em 
aprofundar a relação com esse “outro”, por considerá-lo desagradável, insignificante ou inferior.

Diante das reflexões feitas até o momento, percebe-se que, enquanto o funcionamento saudável é promovido pela vivência de contatos plenos e dialógicos com o "outro", o adoecimento psicológico tem como base a experiência intensa e frequente de contatos interrompidos e não dialógicos, nos quais são introjetados conceitos, valores, normas e exigências impostas arbitrariamente pelo "outro" de grande significação afetiva para o indivíduo, propiciando a internalização do conflito "dominador-dominado”, como explica Perls (1975/1977):

O potencial humano é diminuído tanto pelas ordens não apropriadas da sociedade, como pelo conflito interno. A parábola de Freud sobre as duas serventes brigando, resultando em ineficiência é, na minha opinião, novamente uma meia verdade. Realmente são os patrões que brigam. (...) Na minha linguagem, eu chamo os patrões que brigam de dominador (topdog) e dominado (underdog). A batalha entre os dois é tanto interna quanto externa. O dominador pode ser descrito como exigente, punitivo, autoritário e primitivo. (...) Integração e cura só podem ser conseguidas quando a necessidade de controle entre dominador e dominado cessa (pp. 24-25).

Conforme foi abordado anteriormente, é no contexto familiar autoritário e controlador, que a criança vivencia o conflito "dominador-dominado", que ao ser internalizado, irá produzir as neuroses. Esse conflito é, para criança, um verdadeiro impasse existencial, no qual ela vivencia uma situação que é, ao mesmo tempo, intolerável e inevitável. Sentindo-se totalmente dependente e impotente diante de seu “dominador", a criança se vê obrigada a fazer o que é exigido por este, embora seja incompatível com seus interesses, para evitar a possibilidade de ser punida, ou abandonada por ele. Nesta situação, ela não encontra outra saída a não ser submeter-se completamente às vontades do "dominador”, abrindo mão daquilo que é essencial à sua autorrealização, o que favorece a introjeção de mensagens bionegativas, tais como: eu não sou boa o suficiente; eu faço tudo errado; eu sou culpada (real introjetado); "eu tenho que ser melhor, mais obediente, controlada e cuidadosa” (ideal introjetado), que irão favorecer o desenvolvimento das neuroses caracterizadas por comportamentos dependentes, tímidos, retraídos, exigentes, perfeccionistas e ansiosos.

No contexto indulgente e permissivo, o conflito e o impasse existencial é vivenciado pela criança, na medida em que ela precisa ser protegida, orientada e contida pelo "outro", mas percebe que esse "outro" não é forte, seguro, ou maduro o suficiente para lhe dar proteção e orientação, deixando de colocar os limites indispensáveis à sua segurança e crescimento. Ao se sentir totalmente insegura e desamparada, a criança introjeta as mensa- gens induzidas pela fragilidade e impotência do adulto: eu tenho que ser forte; eu tenho que me controlar; eu não posso falhar; eu tenho que me virar sozinha (ideal introjetado, que vai funcionar como dominador no neurótico com traços obsessivo-compulsivos). Ela também pode introjetar mensagens como essas: eu sou especial; eu sou melhor que os outros; eu mereço ter tudo que quero (real introjetado, que vai atuar como dominador no neurótico com traços narcisistas).

São esses "eus introjetados" (real e ideal) que irão funcionar como "eu dominador". Na tentativa de minimizar o conflito interno gerado pelas incoerências entre as experiências vividas ("eu dominado") e as representações deturpadas de si mesmo ("eu dominador"), o neurótico interrompe o contato com o "outro" e consigo mesmo de forma crônica e obsoleta. Ao interromper o contato como o "outro", ele perde a oportunidade de assimilar o novo e transformar o campo, bloqueando, assim, sua autorrealização e seu crescimento. Na interrupção do contato consigo mesmo, o neurótico desconhece, nega ou distorce algumas de suas experiências e características que, embora sejam inerentes a "si mesmo" (eu dominado), são incompatíveis com os introjetos tóxicos (eu dominador).

O “eu dominador” é um tirano implacável e exigente, cujas imposições, quase sempre, emergem como figura, sobrepondo-se às demandas do "eu dominado", as quais permanecem no fundo. No entanto, podem existir momentos de extrema tensão, em que as necessidades do "eu dominado" se tornam urgentes e atingem o primeiro plano da consciência fazendo com que este se rebele contra seu "dominador" e, apesar de sua timidez e fragilidade, consiga assumir o poder, satisfazendo seus desejos, através de atitudes ousadas, impulsivas e inconsequentes, que são, muitas vezes, incoerentes com os valores e normas da sociedade, como acontece com algumas pessoas que manifestam comportamentos extremamente descontrolados, imaturos, ou caracteristicamente antissociais. É assim que, no processo de autorregulação organísmica, a "função ego" enfraquecida pelo conflito "dominador-dominado", perde sua capacidade de fazer ajustamentos criativos, cedendo espaço para a "função id”, que em casos de emergência assume, naturalmente, o controle da situação.

No processo de constituição das psicoses, como foi explicado antes, a extrema fragilidade das fronteiras e da "função ego" do self, causada pelo intenso conflito dominador-dominado vivenciado no mundo tanto externo, quanto interno, faz com que o "Eu total" perca sua unidade, fragmentando-se em vários "eus” desconectados um do outro e em constante luta entre si, produzindo pensamentos e sentimentos opostos, que se alternam e mudam rapidamente. Isto faz com que as figuras, referentes às prioridades do self, não se destaquem inteiramente do fundo, nem permaneçam o tempo suficiente para que sejam completadas. Sendo o fundo constituído 
por figuras inacabadas, conflitos mal resolvidos e introjetos tóxicos desintegrados da totalidade do self, as novas figuras são contaminadas pelas experiências vivenciadas anteriormente e pelas polaridades alienadas de "si mesmo”, fazendo com que a percepção do campo atual seja completamente distorcida, desencadeando delírios e alucinações.

Quanto ao processo de constituição das neuroses, é importante enfatizar que o enfraquecimento das fronteiras e da função "ego" do self faz com que as interrupções do contato se tornem padrões rígidos de funcionamento, ou ajustamentos conservativos, caracterizados pelas tendências para fixação das fronteiras na abertura ou no fechamento. Nessas duas formas de fixação, os sentimentos de "menos valia" e impotência, sejam como figura ou fundo, favorecem a aproximação, confiança e aceitação do "outro", ou o afastamento, desconfiança e rejeição deste. Sendo assim, enquanto no funcionamento fixado na abertura o "outro" é visto como sendo essencialmente bom e confiável, representando a possibilidade de equilíbrio, satisfação, vantagem e bem estar, no fechamento crônico das fronteiras do self, o "outro" é encarado como sendo essencialmente mau e traiçoeiro, com grande probabilidade de lhe proporcionar desequilíbrio, frustração, desvantagem e mal estar.

Os neuróticos com fixação de suas fronteiras na abertura, portanto, acreditam que podem ter uma vida mais tranquila e prazerosa, na medida em que conseguirem conquistar a confiança, o respeito e o apoio dos outros, procurando, compulsivamente, atender às expectativas destes. Devido ao sentimento de menos valia, fragilidade e impotência em relação à maioria das pessoas, esse tipo de neurótico costuma desenvolver estratégias de sedução e manipulação, desempenhando papéis (bonzinho, coitadinho, certinho, etc.), que facilitem o reconhecimento e o acolhimento por parte daqueles com os quais convive diariamente. Essas características neuróticas correspondem à descrição feita pelo DSM-IV dos Transtornos da Personalidade Dependente, Borderline e Histriônica.

A característica essencial do Transtorno da Personalidade Dependente é uma necessidade invasiva de ser cuidado, que leva a um comportamento submisso e aderente e ao medo da separação. (...) Os comportamentos dependentes e submissos visam a obter atenção e cuidados e surgem de uma percepção de si mesmo como incapaz de funcionar adequadamente sem o auxílio de outras pessoas. (...) Como temem perder o apoio ou aprovação, muitas vezes têm dificuldade em expressar discordância de outras pessoas, especialmente aquelas das quais dependem. (...) Eles não ficam zangados, quando seria adequado, com as pessoas cujo apoio e atenção necessitam, por medo de afastá-las (American Psychiatric Association, 1995, p. 627).
Conforme descrição do DSM-IV, no Transtorno da Personalidade Borderline também é marcante o sentimento de vazio crônico e de dependência em relação ao "outro", produzido por uma percepção de "si mesmo" como alguém sem valor e incapaz de sobreviver por conta própria. A diferença é que no Borderline existe uma grande instabilidade e impulsividade emocional, na qual o sujeito valoriza e ama intensamente o "outro", mas, de uma hora para outra, o despreza e o odeia com a mesma intensidade. Essa instabilidade está relacionada à alternância de fortes sentimentos de satisfação e frustração, acolhimento e abandono, vivenciados na relação com o "outro", com quem mantém ligação afetiva. Outro aspecto desse tipo de transtorno é a automutilação recorrente, utilizada como forma de manipulação, e a fragilidade acentuada do sentimento de self.

Tanto no Transtorno Borderline quanto no Transtorno Dependente, o indivíduo manifesta medo do abandono, mas o "borderline" reage a esse abandono com raiva e exigências, ao passo que o "dependente" reage com crescente humildade e submissão, buscando urgentemente um novo relacionamento que lhe dê a segurança e o apoio que ele tanto necessita. Os indivíduos com Transtorno da Personalidade Histriônica, como no Transtorno da Personalidade Dependente têm uma forte necessidade de amparo e aprovação, podendo parecer infantis e demasiadamente apegados. Entretanto, enquanto o "dependente" se caracteriza por uma autoanulação e comportamento dócil, o "histriônico" se caracteriza pela exuberância, com exigência ativa de atenção.

Com relação aos padrões fixados no fechamento das fronteiras do self, é necessário esclarecer que eles se caracterizam por três tipos de funcionamento gerados por três formas de distorção da autoimagem: negativa, positiva primária e positiva secundária, associadas à percepção do "outro" como alguém que é potencialmente mau e traiçoeiro, ou essencialmente insignificante e culpado, por isso, merece sofrer.

O primeiro tipo de fixação no fechamento se correlaciona com o Transtorno de Personalidade Esquiva e tem como base uma distorção "negativa" da autoimagem, na qual a pessoa se sente frágil, inferior e impotente em relação aos outros, os quais são percebidos como ameaçadores, precisando, portanto, se proteger ou evitar o contato com eles. O segundo tipo de fixação no fechamento das fronteiras do self se desenvolve a partir de uma distorção "positiva primária" da autoimagem, correspondendo ao "padrão egotista” de comportamento, tal como é definido e descrito pela abordagem gestáltica, que se correlaciona com os Transtornos da Personalidade Narcisista e Antissocial nos aspectos referentes à tendência do indivíduo para ser egocêntrico, volúvel, superficial, explorador, arrogante, prepotente, insensível e destituído de empatia.

Segundo Dias (1994), o "egotista” tem uma autoconsciência exacerbada, isto é, ele costuma vigiar excessivamente suas fronteiras, selecionando criteriosamente tudo 
que entra e sai de seu sistema, com medo de se entregar afetivamente ao "outro" e ser dominado ou sufocado por este. Nestas circunstâncias, como forma de defesa, ele mantém suas fronteiras fixadas no fechamento, interrompendo seus contatos, através de mecanismos como a retroflexão e a projeção, permanecendo emocionalmente isolado em relação à maioria das pessoas, uma vez que sempre conta com a possibilidade de ser traído, invadido ou abusado em seus relacionamentos. Além disso, o "egotista" constrói e se mantém fixado a uma imagem idealizada de "si mesmo", alimentando um falso desprezo pelo "outro", enquanto o "eu” é ilusoriamente enaltecido pela aquisição de características irreais de extremo valor, capacidade e poder.

Dessa maneira, tanto os "narcisistas", quanto os "antissociais" podem ser considerados pessoas "egotistas", na medida em que funcionam como crianças egocêntricas, mimadas e sem limites, que só se preocupam com a satisfação de seus próprios desejos, sem levar em consideração as condições e as demandas do meio. No Transtorno Narcisista da Personalidade, embora o sujeito dependa do "outro" para ter a confirmação de seu próprio valor, promovendo, assim, sua satisfação e seu equilíbrio, essa dependência é frequentemente negada. O narcisista, como todo neurótico, no fundo, se sente menor e menos capaz que o "outro", mas, por conta da desconfiança, medo ou desprezo em relação a este, ele controla a aproximação e o envolvimento com a maioria das pessoas, para não correr o risco de revelar e encarar suas próprias limitações, ameaçando seu "eu idealizado" construído por uma distorção "positiva primária” da autoimagem.

No terceiro tipo de fixação no fechamento, desenvolvido através de uma distorção "positiva secundária" da autoimagem, o indivíduo "egotista”, além de manifestar os traços que caracterizam o segundo tipo, que é essencialmente narcisista, sua personalidade também evidencia aspectos que, provavelmente, foram desencadeados pelas experiências de abuso e vitimização vivenciadas na infância ou adolescência, os quais correspondem aos critérios para o diagnóstico diferencial do Transtorno da Personalidade Antissocial em relação ao Transtorno Narcisista: dificuldade para adequar-se às normas sociais, propensão para enganar ou ludibriar os outros para obter vantagens pessoais, impulsividade, agressividade, irresponsabilidade consistente e ausência de remorso.

Como se pode perceber, a personalidade antissocial, psicopata ou perversa, embora compartilhe alguns aspectos com a personalidade "narcisista", o indivíduo "antissocial" se diferencia basicamente pela autoestima fortalecida, pela raiva e agressividade, com necessidade de controlar e dominar os outros, para não correr o risco de ser controlado e dominado por eles.

Os indivíduos com este transtorno não se conformam às normas pertinentes (...) (...) desrespeitam os desejos, direitos ou sentimentos alheios. (...) As decisões são tomadas ao sabor do momento, de maneira impensada, sem considerar as consequências para si mesmos ou para outros. (...) tendem a ser irritáveis ou agressivos e podem repetidamente entrar em lutas corporais ou cometer atos de agressão física (...) tendem a ser consistente e extremamente irresponsáveis. (...) demonstram pouco remorso pela consequência de seus atos. (...) podem acreditar que todo mundo está aí para "ajudar o número um” e que não se deve respeitar nada nem ninguém para não ser dominado (American Psychiatric Association, 1995, pp. 656-657).

O medo de ser dominado confirma a hipótese de que o Transtorno Antissocial se constitui em um contexto familiar autoritário, controlador e frustrador, propiciando a distorção "positiva secundária” da autoimagem como forma de defesa contra os sentimentos de inferioridade, vulnerabilidade e impotência produzidos por situações de impasses existenciais e de conflito "dominador-dominado", que favorecem a introjeção de mensagens bionegativas e a fixação das fronteiras do self na abertura.

Embora em alguns casos, o "antissocial”, ou o "perverso", no fundo, possa se sentir inferior, vulnerável e impotente, o que emerge como figura são sentimentos de superioridade, força e poder gerados pela identificação com seu "dominador". A suposição é de que, apesar desse indivíduo, durante uma parte de sua infância, ter alimentado a ilusão de que sua segurança e seu bem-estar poderiam ser alcançados através do contato afetivo com o "outro dominador", a partir de uma determinada fase de sua vida, devido às várias experiências de abuso e vitimização produzidas por esse "outro", ele desiste dessa ideia e começa a lutar pelo completo afastamento emocional em relação aos "outros” em geral, para não correr o risco de ser abusado novamente.

Por esse motivo, é coerente dizer que o "antissocial" pode ser, no fundo, um neurótico que encontrou um jeito de não permanecer no papel humilhante e sofrido de "dominado", identificando-se com seu "dominador" e reproduzindo o comportamento deste em suas relações interpessoais. Por outro lado, certos neuróticos, podem ser encarados como "perversos" disfarçados de "coitadinhos", "bonzinhos" ou "certinhos", pois, embora, muitas vezes, sinta inveja e raiva dos outros, não têm coragem suficiente para enfrentá-los, desenvolvendo formas indiretas e camufladas de obter vantagens sobre eles.

A distorção "positiva secundária” da autoimagem, no entanto, também pode ser responsável pelo desenvolvimento de outros padrões de funcionamento fixados no fechamento, como aqueles que evidenciam um sentimento de desconfiança e suspeita em relação aos outros, apontado como um dos critérios diagnósticos para o Transtorno da Personalidade Paranóide e aqueles que se caracterizam pela extrema necessidade de controle e perfeição encontrada no Transtorno Obsessivo-compulsivo. 


\section{Considerações finais}

Neste trabalho foi descrito o processo de formação das psicopatologias numa perspectiva gestáltica, concluindo-se que os funcionamentos neurótico, psicótico e antissocial se desenvolvem a partir da vulnerabilidade ou desintegração do "eu", favorecida pela vivência de impasses existenciais e pela internalização de mensagens bionegativas, que propiciam a distorção da percepção interna e externa, a utilização crônica de interrupções do contato e a fixação das fronteiras na abertura ou no fechamento, como forma de ajustamento conservativo.

Em síntese, nas psicoses, a grande tensão gerada pelo conflito "dominador-dominado" gera a desintegração do self, como consequência da falência total de suas fronteiras e funções, impossibilitando a diferenciação entre figura e fundo, fantasia e realidade, "eu" e "tu". No neurótico, essa tensão acontece em grau menor, produzindo o enfraquecimento das fronteiras e o distúrbio das funções do self, responsável pela criação e cristalização de interrupções de contato, na tentativa de minimizar o sofrimento imposto pelo "dominador" nos mundos interno e externo. No antissocial, a mesma tensão gera a explosão, ou a revanche do "dominado" contra seu "dominador", na qual ele, enquanto vítima, se identifica com seu agressor, tornando os outros reféns de seu egoísmo, frieza, arrogância, prepotência e raiva.

\section{Referências}

American Psychiatric Association (1995). DSM-IV, Manual Diagnóstico e Estatístico de Transtornos Mentais ( $4^{\mathrm{a}}$ ed. Revisada). Porto Alegre: Artes Médicas.

Dias, C. M. A. (1994). Os distúrbios da fronteira de contato: Um estudo teórico em Gestalt-Terapia. Dissertação de Mestrado, Universidade de Brasília, Brasília.

Hycner, R. (1995). De Pessoa a Pessoa: psicoterapia dialógica. São Paulo: Summus.
Perls, F. S. (1977). Gestalt-Terapia e Potencialidades Humanas. Em John O. Stevens (Org.), Isto é Gestalt (pp. 19-27). São Paulo: Summus (Original publicado em 1975).

Perls, F. S. (1977). Gestalt-Terapia Explicada. São Paulo: Summus (Original publicado em 1969).

Perls, F. S. (1981). Abordagem Gestáltica e Testemunha Ocular da Terapia. Rio de Janeiro: Zahar Editores (Original publicado em 1973).

Perls, F. S. (2002). Ego, Fome e Agressão: uma revisão da teoria e do método de Freud. São Paulo: Summus (Original publicado em 1947).

Perls, F. S., Hefferline, R., \& Goodman, P. (1997). Gestalt-Terapia. São Paulo: Summus (Original publicado em 1951).

Tenório, C. M. D. (2003a). Os Transtornos da Personalidade Histriônica e Obsessivo-Compulsiva na Perspectiva da Gestalt-Terapia e da Teoria de Fairbairn. Tese de Doutorado, Universidade de Brasília, Brasília.

Tenório, C. M. D. (2003b). O Conceito de Neurose em GestaltTerapia. Revista Universitas Ciências da Saúde, 1(2), 239-251.

Tenório, C. M. D. (2005). O Self eu o Eu nos Transtornos Histriônico e Obsessivo-Compulsivo da Personalidade. Anais do XI Encontro Goiano da Abordagem Gestáltica, pp. 187-199.

Carlene Maria Dias Tenório - Psicóloga graduada pela Universidade Federal do Ceará (UFC), Especialista em Gestalt-Terapia, Mestre e Doutora em Psicologia Clínica pela Universidade de Brasília (UnB), Professora do Centro Universitário de Brasília (UniCEUB) e membro efetivo do corpo docente do Instituto de Gestalt-Terapia de Brasília (IGTB). Endereço Institucional: SEPN 707/907, Campus do UniCEUB, 70790-075, Brasília-DF - Fone: (61) 3340.1046 E-mail: carlenedtenorio@yahoo.com.br

Recebido em 18.09.11 Primeira Decisão Editorial em 03.01.12 Segunda Decisão Editorial em 14.12.12 